\title{
Merchandising social \\ na telenovela brasileira
}

\author{
Lisandro Nogueira* \\ Lourival Belém Júnior**
}

\section{Resumo}

A partir do final dos anos 80 surge um novo tipo de propaganda na televisão brasileira: o merchandising social. Aproveitando o descaso dos governantes do País, as telenovelas começam a incorporar em sua trama certas campanhas de interesse público. A novela "Explode Coração", por exemplo, dedicou-se a uma sistemática campanha em favor das crianças desaparecidas.

Palavras-chave: merchandising; televisão brasilcira; telenovela; propaganda política.

No período compreendido entre 1970 e 1991 a novela das oito conseguiu um patamar de interesse que a distingue das outras novelas nacionais, das soap operas americanas e principalmente das congêneres latinas. Quem angariou esse interesse foram os melodramas atualizados, escritos por Lauro Cesar Muniz, Silvio de Abreu, Benedito Ruy Barbosa, Gilberto Braga, Braulio Pedroso e Cassiano Gabus Mendes. Esse tipo de melodrama inseriu algumas atualizações num gênero marcadamente conservador.

$\mathrm{E}$ quais foram essas atualizações? a) $\mathrm{O}$ anti-herói protagonizado por Beto Rockfeler e Felipe Barreto é menção ao cínico anti-herói de $O$ acossado de Jean-Luc Godard; b) a inserção da música popular brasileira nas trilhas sonoras adveio da força evolutiva da bossa nova e do tropicalismo - inseridos nas novelas pelos autores fascinados pelo charme vanguardista daqueles anos em

* Jornalista, mestre em Comunicação pela ECA/USP, doutorando na PUC-SP, professor na Faculdade de Comunicação e Biblioteconomia da UFG e membro do Cineclube Antônio das Mortes.

** Médico, cineasta e membro do Cineclube Antônio das Mortes. 
ebulição; c) a discussão de temas atuais (a mulher pós-pílula inserida no espaço social e os problemas da ética na política) em várias novelas entre 1969-91; e d) a incorporação de estratégias de marketing nas ações dramáticas.

Esses melodramas no entanto perderam força depois do fracasso monumental de audiência de $O$ dono do mundo (1991). As atualizações se tornaram caricaturas após os anos noventa $\mathrm{O}$ que as novelas incorporaram daquele contexto se perdeu ia diluição fria e consistente patrocinada pela padronização e repetição da indústria cultural.

Uma das inovações fincou raízes, é regada pela indústria da televisão e rende frutos e dividendos. O merchandising ( a publicidade incorporada no contexto dramático) acoplado nas novelas desde Beto Rockfeler (1969) se tornou uma das principais fontes de patrocínio de uma produção cara e complexa - um capítulo tem um custo entre 35 e 50 mil dólares. A inovação, de tão rentável, rendeu departamentos específicos nas emissoras visando à comercialização dos merchandisings.

\section{1 merchandising social}

$\mathrm{O}$ merchandising foi sendo aprimorado e começou a transbordar alcançando leitos de outros rios. A incorporação de temáticas urbanas pelos autores foi diluída no novo tipo de merchandising surgido no final dos anos oitenta, pois de tanto abordar temáticas da realidade brasileira as emissoras descobriram o "merchandising social". Num primeiro momento, devido às imensas carências e dívidas sociais, a inserção de campanhas de saúde nas novelas foi saudada e louvada. Aproveitando o descaso das elites que dominam o Estado e seus aparelhos, as telenovelas, com ampla penetração na sociedade brasileira, ocuparam o espaço e, através dos "merchandisings sociais", substituíram em alguns casos o papel do poder público. Tanto a campanha do Betinho foi inserida na novela das oito como as campanhas pela diminuição do colesterol na alimentação. As novelas a partir daí não seriam mais um narcótico alienante pois estariam contribuindo para a suavização dos problemas dos "menos favorecidos". 


\section{6}

O mais recente exemplo de merchandising social se deu na novela Explode coração, de Glória Perez. As mães que perderam seus filhos ganharam guarida na benevolência do melodrama com o apoio maciço dos telespectadores. A ficção mais uma vez deu lugar à realidade e todos os dias fotos de crianças desaparecidas e supostamente seqüestradas apareciam no vídeo. Algumas foram encontradas, o que sugeria o acerto da iniciativa - depois descobriu-se que a maioria das crianças tinha saído voluntariamente de casa.

Assistimos aqui às telenovelas se irmanarem com nossos governantes demagógicos que se apresentam como "administradores voltados para o social" e conclamam "os poderes constituídos a conhecer o país dos miseráveis", responsabilizando supostas "elites" que eles dizem não representar. Como nas iniciativas que simulam preocupação com o sofrimento do povo brasileiro na dramaturgia contemporânea, as ações políticas se resumem a implementar programas assistencialistas com capacidade financeira irrisória ou se propõem a criar ou manter "fundos sociais de emergência" que, hipocritamente, exploram falsas finalidades sociais com objetivos camuflados.

Percebemos um deslocamento de responsabilidades em que as telenovelas e algumas manifestações artísticas cumprem uma função ideológica fundamental. Deixamos preceitos éticos e nos preocupamos em ganhar dinheiro como advogados, engenheiros, médicos, artistas e desportistas famosos, numa atitude narcisista comum nas classes médias que lavam as mãos para a miséria social e se lixam para o trabalho intelectual. Como diz Robert Kurz (O colapso da modernização, Ed. Paz e Terra) em artigo jornalístico, os "intelectuais estetizam a miséria e a exploram comercialmente; os sofrimentos daqueles que passam fome são transformados em publicidade".

\section{A citação glamourizante}

O melodrama abarca os problemas brasileiros por motivos que vão muito além da filantropia (e aqui importa ressaltar que filantropia e solidariedade são conceitos distintos). Há uma queda gradativa da audiência e uma crise de criatividade que comprometem for-

Comun. inf., v.1, n. 1, p. 114-119, jan./jun. 1998 
mato e conteúdo. No afã de grande audiência, pois sobrevivem dela, as novelas apelam para os recursos mais variados. E foi justamente por esses dois motivos que nasceu mais um tipo de merchandising. Inaugurado com Pantanal, que mostrou o esgotamento da "novela tipo-zona-sul-carioca", o merchandising ecológico-cultural abriu um filão rural liderado por Benedito Ruy Barbosa (escritor) e Luis Fernando Carvalho (diretor). Juntos realizaram Renascer. Nela já se encontrava o embrião do esgotamento dos "melodramas atualizados". Isso quer dizer que quando não há riqueza no texto apela-se para o potencial sedutor das imagens, que "nos convidam a contemplar o mundo como se fosse um corpo nu" (Frederic Jameson, As marcas do visível - Ed. Graal), quando não apelam para a pornografia explícita. Longas e enfadonhas, principalmente a partir do décimo-primeiro capítulo, as novelas partiram para captar imagens da natureza brasileira. Paralelamente ao ornamento ecológico-cultural das imagens visando cobrir textos frágeis, a dupla se enveredou pelo caminho da citação glamourizante.

Uma das características da cultura pós-moderna é a contaminação do entretenimento pela "alta cultura". Há um desejo no interior da indústria cultural em legitimar seus produtos com referências aos clássicos da cultura universal. $\mathrm{O}$ que se produz na verdade é um pastiche com recheio de chantilly. Em Renascer sobram pastiches e as citações são constantes. A principal seqüência de Deus e o diabo na terra do sol, de Glauber Rocha, Corisco sendo fulminado por Antônio das Mortes, é revivida com um texto fragilíssimo. Mas, neste caso, o que conta para a indústria televisiva são os créditos junto a um certo tipo de público formador de opinião. Não se percebem a redundância $\mathrm{e}$ a cópia anacrônica. À novela é conferido prestígio por transferência. É irônico que a própria emissora não programe o original, pois raramente se vê Glauber Rocha na televisão. Ora, o que se pretende é um "brilho de aluguel" e apresentar a jóia original já seria pedir demais ao vampiro dissimulador.

Às citações glamourizantes e ao regionalismo que camuflam fragilidades se agrega também o maniqueísmo no trato da política por parte da dupla Barbosa e Carvalho. Num estudo estimulante, Mauro Porto (Comunicação e Política, Cebela, 1995, 


\section{8}

p. 55-76) detecta em Renascer a repugnância à política e a desqualificação do governo e do Estado. O diálogo entre José Inocêncio e Noberto sobre a venda de uma fazenda em Goiás para um político desencadeia diálogos apressados e superficiais, amalgamando toda a atividade política com corrupção e demagogia.

A referência à desqualificação do governo e do Estado aparece quando o filho do coronel, José Augusto, afirma, conforme Porto, que "largar a coisa na mão do governo é fogo. Empata mesmo. Tudo fica mais caro, tudo fica mais difícil (...)". No decorrer da seqüência não se sai da superficie e sequer se pergunta quem administra esse Estado e quem são aqueles (grupos ou instituições) que desqualificam governos. Suas generalizações são grosseiras e maniqueístas. Nunca a pecha de conservadoras vestiu tão bem as novelas brasileiras.

As generalizações em relação à política são comuns no solo melodramático nacional. Gilberto Braga, por exemplo, não se cansa de cometê-las em Vale tudo, $O$ dono do mundo e Anos rebeldes. Por essas e outras características as novelas contribuem para reforçar idéias e comportamentos conservadores.

Podemos aqui também traçar um paralelo entre essas desqualificações do Estado e governos e o que se ouve nas falas lingüísticas cotidianas. A hipermidiatização (a comunicação ocupando todos os espaços) dos fenômenos sociais e da vida política aumenta cada vez mais a frustração de cidadãos passivos, sem voz e com grande sentimento de inutilidade social. Os cidadãos vivem se lamuriando das péssimas condições de vida, da instabilidade econômica, das repercussões emocionais e da política como antro de corrupção, mas sentem que seus gritos não desfazem sua ansiedade histérica, talvez porque não compreendem exatamente o que se passa e não vêem canais legítimos de amplificação de suas vozes.

Assim, quando assistem ao que foi comentado acima, sentem o efeito catáftico tranqüilizador proporcionado pela "repercussão" do que vêm dizendo na vida diária. O gozo, mesmo insatisfatório, lhes dá energia suficiente para aguardar a próxima frustração e revela a importância da telenovela, com suas atualizações dentro do espaço midiático da socie-

Comun. inf., v.1, n. 1, p. 114-119, jan./jun. 1998 
dade contemporânea, para a manutenção de relações assimétricas de poder.

\section{Abstract}

Beginning in the late 1980's a new kind of propaganda campaign sprung up in brazilian television: social merchandising. Because of the lack of interest of the government, television soap-operas began to incorporate with-in the plot of the story campaigns of public intevest. The soap-opera "Explode coração" for example dedicated a systematic campaign for lost children.

Key words: murchandising; brazilian television; soap-opera; political propaganda.

\section{Referências bibliográficas}

KURZ, Robert. O colapso da modernização. São Paulo : Paz e Terra, 1993.

FREDRIC, Jameson. As marcas do visivel. São Paulo : Graal, 1995.

PORTO, Mauro. Comunicação e política. Brasília : Cebela, 1995. 